\title{
Dual response of Arabian Sea cyclones and strength of Indian monsoon to Southern Atlantic Ocean
}

\author{
Vittal Hari ${ }^{1}$ (1) $\cdot$ Amey Pathak ${ }^{2} \cdot$ Akash Koppa $^{3}$
}

Received: 9 April 2020 / Accepted: 8 December 2020 / Published online: 23 December 2020

(C) The Author(s) 2020

\begin{abstract}
Variability and trends of the south Asian monsoon at different time scales makes the region susceptible to climate-related natural disasters such as droughts and floods. Because of its importance, different studies have examined the climatic factors responsible for the recent changes in monsoon strength. Here, using observations and climate model experiments we show that monsoon strength is driven by the variations of south Atlantic Ocean sea surface temperature (SASST). The mechanism by which SASST is modulating the monsoon could be explained through the classical Matsuno-Gill response, leading to changes in the characteristics of vertical wind shear in the Arabian Sea. The decline in the vertical wind shear to the warming of SASST is associated with anomalous lower (upper)-level easterlies (westerlies). This further leads to a strong increase in the frequency of the Arabian Sea cyclones; and also prohibits the transport of moisture to the Indian landmass, which eventually reduces the strength of monsoon. The conditions in the SASST which drove these responses are aggravated by greenhouse gas emission, revealing the prominent role played by anthropogenic warming. If, with proper mitigation, these emissions are not prevented, further increases in the SASST is expected to result in increased Arabian sea cyclones and reduced monsoon strength.
\end{abstract}

Keywords Arabian Sea cyclones · Indian summer monsoon rainfall · South Atlantic Ocean

\section{Introduction}

The South Asian summer monsoon rainfall, which occurs during June to September (JJAS), has a significant impact on nearly one-half of the world's population. Variation in strength of the monsoon, due to both natural and anthropogenic influences, has a tremendous impact towards increasing the natural disaster risks (Sharma et al. 2020; Vittal et al. 2020a). Considering this, there has been extensive work on understanding the past and future changes in the monsoon using both observed data and climate model simulationsyet many aspects of the monsoon remain poorly understood,

Vittal Hari

vittal.hari@ufz.de

1 Department of Computational Hydrosystems, Helmholtz Centre for Environmental Research, UFZ, Leipzig, Germany

2 Agricultural and Food Engineering Department, Indian Institute of Technology Kharagpur, Kharagpur, India

3 Hydro-Climate Extremes Lab (H-CEL), Faculty of Bioscience Engineering, Ghent University, Coupure Links 653, 9000 Ghent, Belgium leading to uncertainties in future predictions (Shashikanth et al. 2018). Studies show that the south Asian monsoon rainfall (Kitoh et al. 2013), Hadley circulation over the Indian ocean (Roxy et al. 2015) and Walker circulations over the Indo-pacific region (Vecchi et al. 2006) have weakened post-1950. To explain this, multiple hypotheses have been proposed in literature, viz., increase in aerosol emissions (Bollasina et al. 2011), Western Indian Ocean warming (Roxy et al. 2015) and changes in land use land cover (Paul et al. 2016).

The hypothesis put forward for explaining the declining monsoons are mostly related to weakening of the monsoon south-westerly winds. However, along with the low-level westerlies, the formation of depressions over Bay of Bengal (BoB), which transport enormous amounts of moisture, also contribute significantly to the mean monsoon rainfall during summer (Vishnu et al. 2016). The decreasing trend in the frequency of monsoon depressions in the BoB is related to anomalous moisture convergence over the western equatorial Indian Ocean caused by an increase in sea surface temperature (Vishnu et al. 2016). Another reason for the reduction in monsoon depressions over the BoB may be linked with 
the episodic surges of moisture transport from the Arabian Sea (AS) (Roxy et al. 2017). Precipitation usually exceeds evaporation in BoB region during summer season and this is maintained by a substantial moisture influx from the AS (Mooley 1973). However, during recent past, the moisture influx from the AS has been reducing significantly which in turn reduced the genesis of monsoon depressions (Roxy et al. 2017). Moreover, while analysing an increase in extreme precipitation over Central India, Roxy et al. (2017) identified that the primary source of moisture is from the Arabian Sea. They quantify that around $36 \%$ of total moisture comes from the AS, while $26 \%$ and $9 \%$ arise from the $\mathrm{BoB}$ and the central Indian Ocean, respectively.

Thus, monsoon depressions in the $\mathrm{BoB}$ are reducing and the dynamics of the Arabian Sea has played a major role in doing so. In addition, the moisture supply from the AS to the Indian rainfall is higher when compared to BoB. However, the climate system over AS has changed significantly during recent past. For example, Evan et al. (2011) and Murakami et al. (2017) showed that the frequency of both pre- (May-June) and post- monsoon (October-December) AS tropical cyclones increased during last decade due to anthropogenic warming. In such a scenario, AS cyclones could inflict some 'collateral damage' on the progress of monsoon over mainland India and the monsoon may remain weak until the storm dissipates, specifically during the month of June when the onset of monsoon happen for most regions of India. Although these cyclones can increase the intensities of extreme precipitation over India (as reported in Roxy et al. 2017), it may weaken the mean monsoons, a mechanism that has not been explored in the previous studies. A recent study by Zhang and Villarini (2019), however, showed that the forcing of the south Atlantic Ocean surface temperature (SASST) can drive changes in the AS cyclones. Nonetheless, the study is conducted during the pre-monsoon season. Moreover, the SASST also significantly alters the monsoon rainfall strengths over India during the monsoon season (June-September) by the Matsuno-Gill responses (Kucharski et al. 2007, 2008, 2009; Pottapinjara et al. 2014; Sabeerali et al. 2019a). The responses of large-scale circulation to SASST forcing feature a strong upper-level cyclone and low-level anticyclone in the Indian ocean basin, including AS and BoB (Kucharski et al. 2009; Zhang and Villarini 2019), which could lead to noticeable impacts on vertical wind shear over the basin, which is crucial to cyclonic activity. Therefore, the main objective of the present study is to examine whether and how the SASST can modulate the frequency of the AS cyclones using both the observations and climate model perturbation simulations, specifically during the monsoon season, and also explore changing dynamics of the Indian summer monsoon in response to SASST anomalous warming. We then extend our analysis with the use of suite of climate model simulations from the Coupled Model
Intercomparison Project phase 5 (CMIP5) to understand how the SASST would change at the end of this century, and underpin the role of the anthropogenic warming in exacerbating such changes.

\section{Data and methods}

We procure a long-term precipitation data for Asian monsoon region from the Climate Research Unit (CRU) (Mitchell and Jones 2005) for the period 1951-2017; with a spatial resolution of $0.5^{\circ}$ at a monthly temporal scale. The monthly sea surface temperature (SST) data for the period 1870-2018 are obtained from HadISST dataset (Rayner et al. 2014) provided by the Met Office Hadley Centre. Details of cyclone tracks and its intensity for the AS for the period 1979-2010 is obtained from India Meteorological Department (IMD), which is a nodal government agency that provides weather services related to cyclones in India that classifies the pressure system from depression to very severe Cyclonic storms. Further, the large-scale atmospheric information, such as low- and high-level wind, is obtained from the National Centers for Environmental Prediction (NCEP)/National Center for Atmospheric Research (NCAR) reanalysis project (NCEP-NCAR-1) (Kalnay et al. 1996) for the period 1951-2017 available at $2.5^{\circ}$ resolution. To examine the characteristics of the mechanism responsible for the changing characteristics of monsoon strength and AS cyclones, we procure the state-of-the-art global climate model simulations from the Coupled Model Intercomparison Project phase 5 (CMIP5, (Taylor et al. 2012); detailed description is provided in Table 1 . To quantify the effect of human activities in the past (1850-2005), three types of monthly forcings are analysed: (1) natural-only (HistNat), (2) green-house emission-only (HistGhG), and historical (Hist). Here, the HistNat simulations contain only the effects of natural forcing (e.g., changes in solar radiation, volcanic eruptions), and the HistGhG consist of only the anthropogenic (i.e., GHG concentrations) effects. Hist, on the other hand, considers both natural and anthropogenic effects. To assess possible future climate scenarios, we procure two Representative Concentration Pathway (RCP) scenarios (4.5 and 8.5), which are available for 2006-2100.

\subsection{Removing the El Niño-Southern Oscillation (ENSO) from the SST}

Given the strong influence exerted by the ENSO on the surrounding areas, particularly over the Atlantic Ocean and Indian mainland (Ju and Slingo 1995; Roy et al. 2019), we isolate the ENSO signal and analyse the independent influence of the SST on the Indian monsoon and AS cyclone. The ENSO influence can be removed by calculating the residual 
Table 1 List of climate models used in the present study

\begin{tabular}{|c|c|c|}
\hline Models & $\begin{array}{l}\text { Horizontal resolution (lati- } \\
\text { tude/longitude) }\end{array}$ & Organization \\
\hline ACCESS1-3 & $145 \times 192$ & $\begin{array}{l}\text { CSIRO (Commonwealth Scientific and Industrial Research Organisation, Australia), and } \\
\text { BOM (Bureau of Meteorology, Australia) }\end{array}$ \\
\hline CanESM2 & $192 \times 256$ & CCCma (Canadian Centre for Climate Modelling and Analysis), Victoria, BC, Canada \\
\hline CNRM-CM5 & $128 \times 256$ & $\begin{array}{l}\text { Centre National de Recherches Météorologiques-Groupe d'études de l'Atmosphère } \\
\text { Météorologique and Centre Européen de Recherche et de Formation Avancée, France }\end{array}$ \\
\hline CSIRO-Mk3-6-0 & $189 \times 192$ & $\begin{array}{l}\text { Australian Commonwealth Scientific and Industrial Research Organization (CSIRO) } \\
\text { Marine and Atmospheric Research, Melbourne, Australia }\end{array}$ \\
\hline GISS-E2-R & $90 \times 144$ & NASA Goddard Institute for Space Studies, United States \\
\hline IPSL-CM5A-LR & $149 \times 182$ & Laboratoire de Météotologic Dynamique and L'Instutut Pierre-Simon Laplace, France \\
\hline IPSL-CM5A-MR & $149 \times 182$ & Laboratoire de Météotologic Dynamique and L'Instutut Pierre-Simon Laplace, France \\
\hline MIROC-ESM & $192 \times 256$ & $\begin{array}{l}\text { Atmosphere and Ocean Research Institute, National Institute for Environmental Studies, } \\
\text { and Japan Agency for Marine-Earth Science and Technology, Japan }\end{array}$ \\
\hline MIROC-ESM-CHEM & $192 \times 256$ & $\begin{array}{l}\text { Atmosphere and Ocean Research Institute, National Institute for Environmental Studies, } \\
\text { and Japan Agency for Marine-Earth Science and Technology, Japan }\end{array}$ \\
\hline MRI-CGCM3 & $368 \times 360$ (rotated pole grid) & Meteorological Research Institute, Japan Meteorological Agency, Japan \\
\hline
\end{tabular}

Spatial resolution of climate model simulations was converted to that of observed HadISST data based on nearest neighbour approach

time series as provided in Eq. 1 (Kucharski et al. 2009: Vittal et al. 2020b);

$S S T_{R}(t)=S S T(t)-S S T_{E N S O}(t)$

where,

$\operatorname{SST}_{E N S O}(t)=b \times N i n o_{3.4}(t)$

where $\mathrm{b}$ is determined using the linear regression between SST at a respective grid and $\mathrm{Niño}_{3.4}$ index.

\subsection{Moisture transport analysis}

The amount of moisture transported to the Indian continent, which is surrounded by oceans, is directly linked to the rainfall activity over the region (Levine and Turner 2012; Pathak et al. 2017; Roxy et al. 2017). Thus, we analyse the condition of moisture transport during our identified largescale atmospheric phenomena in terms of integrated water vapour transport (IVT), the key link between source and sink regions of moisture (Lavers et al. 2015). We use specific humidity and the meridional and zonal wind components from the surface to mid-troposphere pressure levels to calculate the magnitude of IVT (Lavers et al. 2012),

$I V T\left(\mathrm{kgm}^{-1} \mathrm{~s}^{-1}\right)=\sqrt{\left(\frac{1}{g} \int_{1000}^{300} q u d p\right)^{2}+\left(\frac{1}{g} \int_{1000}^{300} q v d p\right)^{2}}$

where $\mathrm{q}$ is the specific humidity $\left(\mathrm{kg} \mathrm{kg}^{-1}\right)$, $\mathrm{u}$ and $\mathrm{v}$ are the zonal and meridional wind components $\left(\mathrm{ms}^{-1}\right)$, respectively, $\mathrm{g}$ is the acceleration due to gravity $\left(\mathrm{ms}^{-2}\right)$, and $\mathrm{dp}$ is the pressure level difference.

\subsection{Dynamic recycling model}

The relative contribution of evaporated water from different ocean sources to the precipitation over the Indian subcontinent (sink) is also analysed using Dynamic Recycling Model [see Martinez and Dominguez (2014) and Pathak et al. (2017) for detailed information]. In this model, the conservation of the total column water vapour is solved by using a classical Lagrangian approach. We use six-hourly fields of vertical integral of eastward and northward water vapor flux to obtain the moisture-weighted wind component in two horizontal directions [see Martinez and Dominguez (2014) and Pathak et al. (2017)] to study the atmospheric moisture transport.

\subsection{Climate model perturbation experiments}

To perform the perturbation experiments, we use atmospheric general circulation model developed by International Centre for Theoretical Physics (ICTP AGCM) (Molteni 2003; Kucharski et al. 2013; Vittal et al. 2020c). Here, we use the latest version (v41) of this model, which consists of 8 vertical levels along-with the horizontal spectral truncation set at $\mathrm{T} 30\left(\sim 3.75^{\circ}\right.$ spatial resolution $)$. This atmospheric model consists of physically based parameterizations of large-scale condensation, shallow and deep convection, short-wave and long-wave radiation, surface fluxes of momentum, heat and moisture, and vertical diffusion. To evaluate the impacts of the SST anomaly on Asian monsoon 
and large-scale circulation, we performed experiments which are integrated for 30 years. Initially, we start the experiment by prescribing the seasonal climatology of SST based on HadISST (CLIM). Further, to evaluate the response of SST anomaly, which could influence the changing characteristics of both the monsoon strength and AS cyclone, the observed composite anomaly of SASST during positive and negative phase for summer monsoon season are superimposed on the seasonal climatology, keeping SST identical to the CLIM experiment for other months. The subtraction of CLIM experiment with the SST anomaly forced experiment then provides the response of large-scale atmospheric circulation, which is associated to the monsoon and AS cyclone, to the SST anomaly.

\section{Results and discussions}

Before we do a comprehensive analysis, it is important to identify large-scale atmospheric circulation patterns which could affect both the monsoon strength and frequency of AS cyclone. For this purpose, we first analyse the association between rainfall over the Indian core monsoon zone and sea surface temperature (SST) during JJAS (Fig. 1a). We identify a prominent negative correlation in the AS, equatorial Pacific Ocean, which also encompasses the ENSO region, and southern Atlantic Ocean SST (SASST). Provided that ENSO exacerbates the strong influence on the surrounding regions, we then isolate the ENSO-independent contribution of SASST on the Indian monsoon (Eq. 1). We notice that negative association between SASST $\left(20^{\circ} \mathrm{S}-1^{\circ} \mathrm{S}\right.$, $30^{\circ} \mathrm{W}-10^{\circ} \mathrm{E}$ ) and the Indian monsoon became more evident (Fig. 1b). To further investigate this association, we spatially aggregate SASST to form SASST index, with ENSO removed, and conduct a grid-wise correlation with monsoon rainfall over the Indian mainland. Figure 1c indeed acknowledges the negative relationship over India, with the highest signal noticed in Central India and the core monsoon zone.

It is hence evident from this initial analysis that the SASST influences the Indian monsoon. This observation has been reported by previous studies (Kucharski et al. 2007, 2009; Pottapinjara et al. 2016; Yadav et al. 2018). SASST mode is similar to ENSO with high SST anomalies in eastern equatorial Atlantic and Gulf of Guinea (GG), however, with a weaker signal and mostly short-lived (Lübbecke et al. 2010, 2018; Burls et al. 2012). Kucharski et al. (2009), Pottapinjara et al. (2014) and Sabeerali et al. (2019a) showed that SASST effects the Indian monsoon through a simple Matsuno-Gill-type response; and this is responsible for the formation of monsoon depressions in the BOB. The warming of SASST causes fewer monsoon depressions, due to reduction in low-level cyclonic vorticity and midtropospheric humidity, which eventually leads to reduced monsoon over India. It is also clear from our analysis that SASST alters the monsoon strength.

With the use of NCEP reanalysis data, we regress the lower ( $850 \mathrm{hpa}$ ) and upper (200 hpa) level wind fields onto SASST from 1951 to 2017 (Fig. 2a, b). The result depicts a strong easterly (westerly) at 850 (200) hpa level, leading to a significant reduction in the wind shear (defined as change in wind speed with respect to 200 and $850 \mathrm{hpa}$ pressure levels) over the AS and BoB. SASST anomaly plot further shows that in recent times (post-1990) they are predominately characterised by a higher number of positive anomaly years (Fig. 2c). From this plot, we extract the information pertaining to the positive and negative phases of SASST. During the positive phase, we do notice easterlies at $850 \mathrm{hpa}$ and westerlies at $200 \mathrm{hpa}$ level, thus leading to the reduction

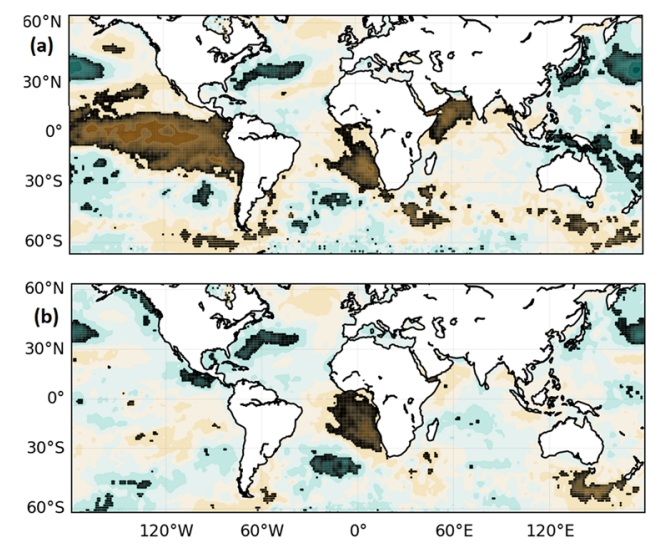

Fig. 1 Association between SST and Indian monsoon rainfall during 1951-2017 during JJAS season. a Grid wise correlation between SST and spatially aggregated JJAS rainfall over the core monsoon region $\left[18.5^{\circ} \mathrm{N}-25.5^{\circ} \mathrm{N}, 74.5^{\circ} \mathrm{E}-84.5^{\circ} \mathrm{E}\right]$. b Same as a, but with ENSO

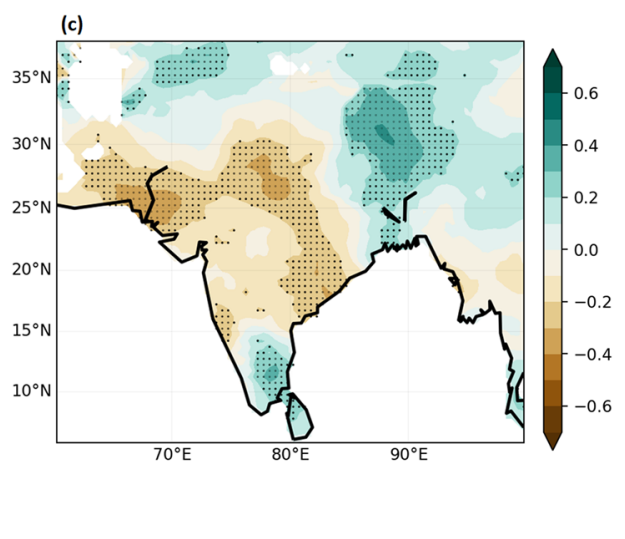

influence removed from JJAS SST. c Association between southern Atlantic Ocean SST and JJAS rainfall over India. Hatched areas represent the locations where correlations are different from zero at $10 \%$ level 

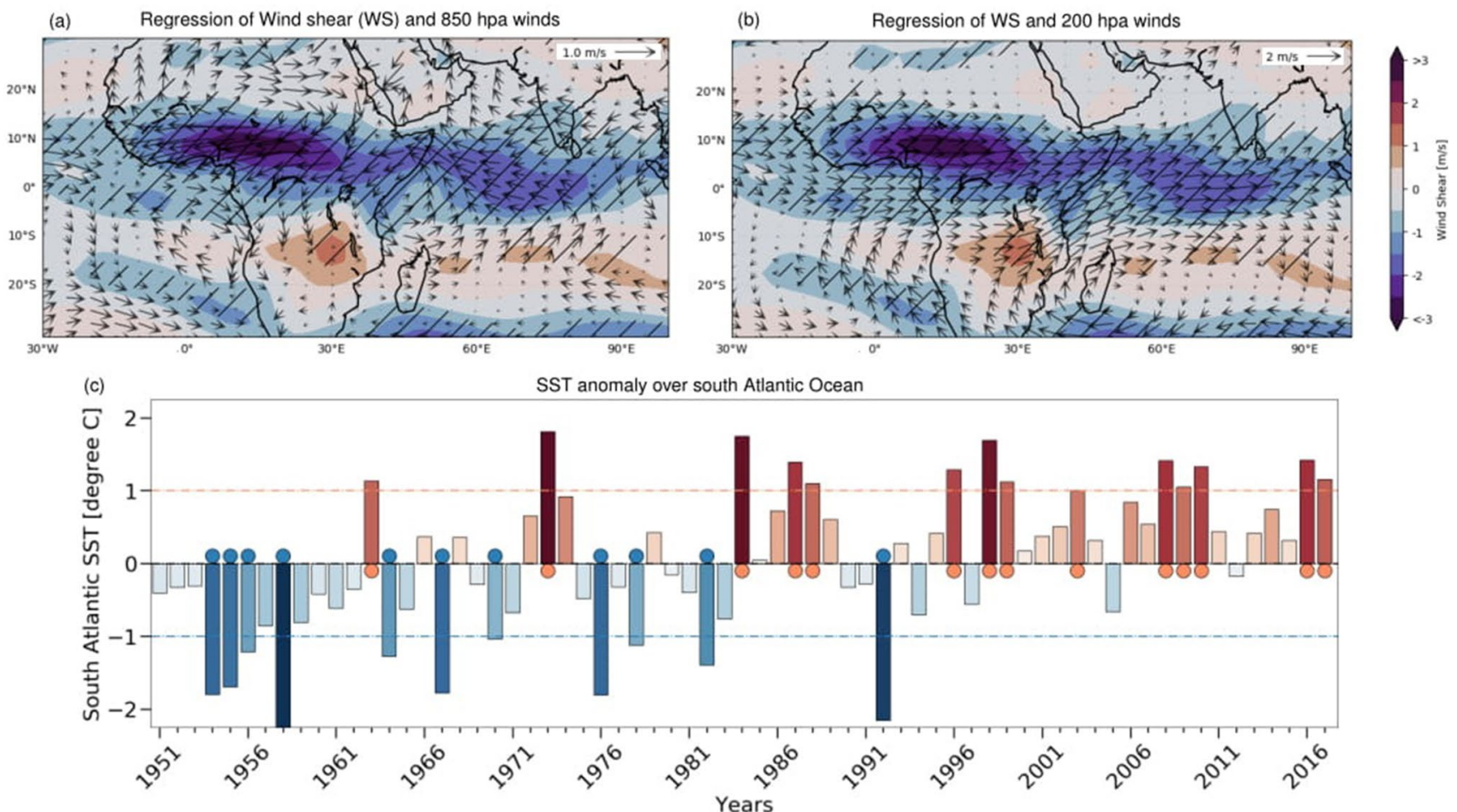

(d) Composite anomaly of WS and $850 \mathrm{hpa}$ winds during positive phase
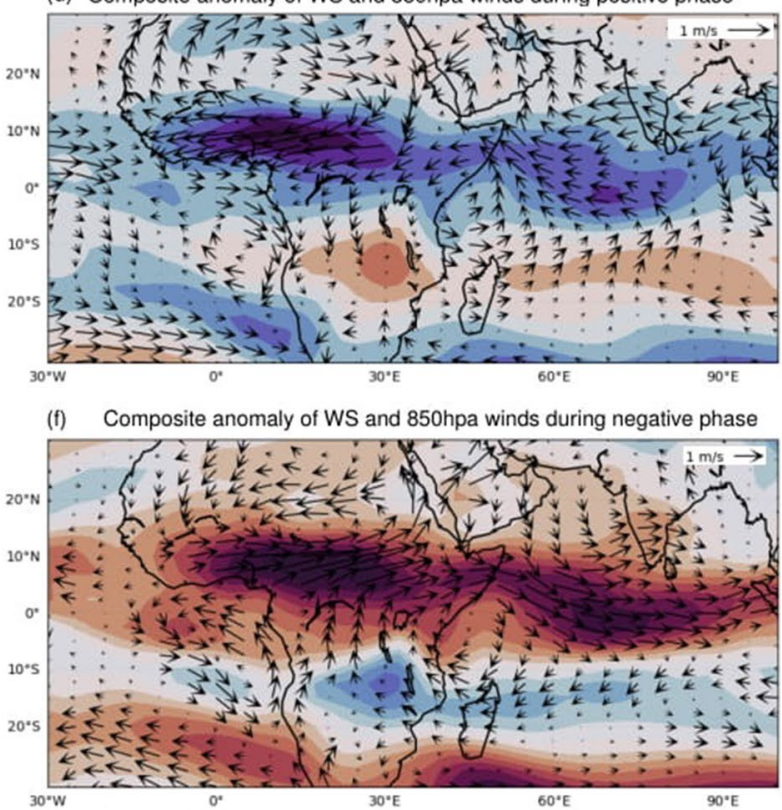

Fig. 2 a (b) Regression of lower (upper) level winds onto SASST from 1951 to 2017, while the shading represents regression of vertical wind shear onto SASST. Hatching shows the regions where differences in anomalies are different at $10 \%$ level. b Bar plot showing SASST anomaly during the summer monsoon season for 1951-2017. Positive (negative) anomalies are represented by red (blue) colour, while the red (blue) dashed line depicts threshold of $1(-1)$ stand-

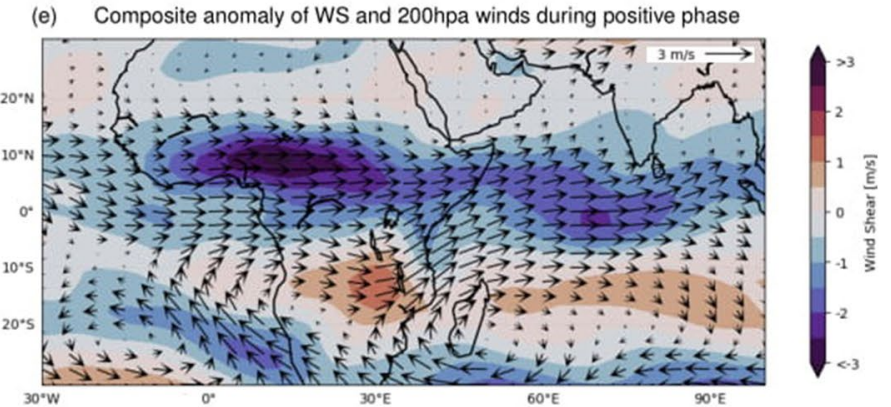

(g) Composite anomaly of WS and $200 \mathrm{hpa}$ winds during negative phase

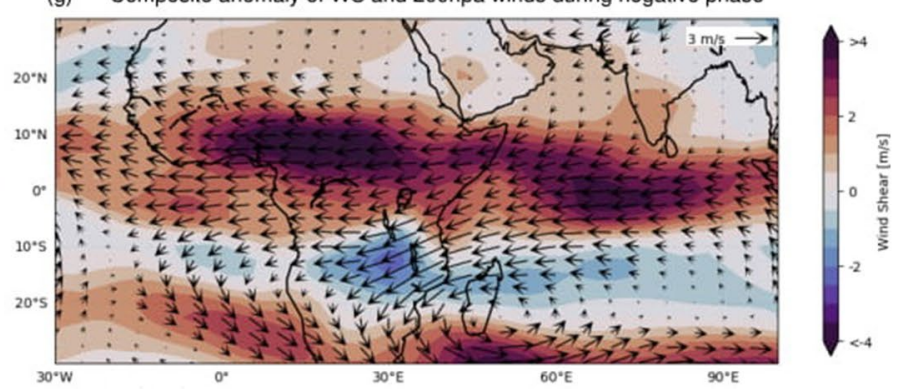

ard deviation. The red (blue) dots represent the years wherein SASST anomaly is greater (less) than $1(-1)$ standard deviation, which is further used to form a positive (negative) phase composites. Composite anomalies of 850 and 200 hpa winds along with vertical wind shear are provided in $\mathbf{d}(\mathbf{f})$ and $\mathbf{e}(\mathbf{g})$, respectively for positive (negative) phase 
in the vertical wind shear (Fig. 2d, e) over AS. This situation could provide a conducive environment for the formation of cyclones over AS (Evan et al. 2011; Wang et al. 2012; Rajeevan et al. 2013). Although, these mentioned studies provide a clear information pertaining to the increased frequency of AS cyclone, the underlying physical mechanism was not clear, which we try to identify in the present study. During the negative phase, however, we notice an increased vertical wind shear with strong westerlies (easterlies) at 850 (200) hpa level (Fig. 2f, g).

The physical mechanism by which the heating anomalies of SASST interconnect to the Indian ocean basin (including Arabian sea) could be explained by a Gill-Matsuno-type quadrupole response (Gill 1980), which is developed by an eddy stream function with kelvin and Rossby waves transporting the signal respectively to the east and to the west (Kucharski et al. 2009). Complete description of the mechanism of SASST on Indian ocean region can be found in Kucharski et al. (2009) and Barimalala et al. (2012). Nonetheless, here, we provide a brief discussion of the same. Warm anomalous SASST signal provides a favourable condition for a rising motion, upperlevel divergence and a minimum velocity potential over equatorial Atlantic and adjoining African region. This condition is balanced by an increased upper-level convergence over Indian ocean and central-western Pacific regions, thereby causing a higher values of velocity potential (Kucharski et al. 2009). However, on the lower levels, opposite anomalies will be formed, indicating a baroclinic response to SASST. Further, in upper-level velocity potential gradient, an upper-level (lower-level) cyclonic (anticyclonic) circulation will be developed, particularly over sub-tropical region, because of Sverdrup balance (Chen 2003; Kucharski et al. 2011). This process further leads to a high-pressure anomaly at the surface over Arabian sea and Indian mainland, triggering anomalous low-level divergence and a weakening of summer monsoon strength over Indian core monsoon zone. Further, at upper levels (low-levels), a warm SASST anomaly leads to westerly (easterly) wind anomalies in Indian Ocean region, including Arabian sea, causing the changes in wind shear characteristics and also does influences a cyclone characteristic over the basin. Additionally, it has also been observed that anomalous warm SASST weakens the time-mean Walker circulation, and it may further contribute to strengthening the teleconnection between SASST and atmospheric circulation over Indian basin (Kucharski et al. 2007, 2008). Figure 3 depicts a schematic representation which encapsulate the principal mechanisms associated with an anomalous warming of SASST.

Overall the analysis from observations showed the influence of SASST in changing large-scale atmospheric characteristics over AS. To comprehend the results procured from observations, we further extend our analysis with the use of climate perturbation experiment. Here, we use ICTP AGCM, which could successfully demonstrate the large and persistent Atlantic SST anomalies forcing the low-level convergent flow, bringing moist air during the African and Indian summer monsoon and modulating the summer climate over these regions, consistent with the observed patterns (Kucharski et al. 2007, 2009; Feudale and Kucharski 2013; Zhang and Villarini 2019). In particular ICTP AGCM could reasonably reproduce the summer monsoon features over India (Fig. 4). Indian summer monsoon season is characterised by the strengthening of south-westerly winds that brings moisture from ocean to Indian main land (Fig. 4a), which can also be seen in ICTP AGCM simulations (Fig. 4b). We further consider the spatial average of rainfall to compute the climatology for all the months. The observed climatology shows a gradual increase of rainfall from June, after onset, reaching peak during July-August and then decrease towards September, followed by a monsoon withdrawal (Fig. 4c). We find that ICTP AGCM could also capture this observed pattern of climatology over India. Considering the fact that the ability of ICTP AGCM in simulating the monsoon characteristics and also reproducing the climatic response of Atlantic SST warming over the Africa and Indian regions, we therefore select this model in our study.
Fig. 3 Schematic representation of the mechanism of SASST teleconnection for an anomalous positive SST and showing its influence on Arabian sea and Indian region, which is adapted from Barimalala et al. (2012). Shading represents the anomalies of surface pressure during the positive phase of SASST, whereas winds at surface level are shown in vectors

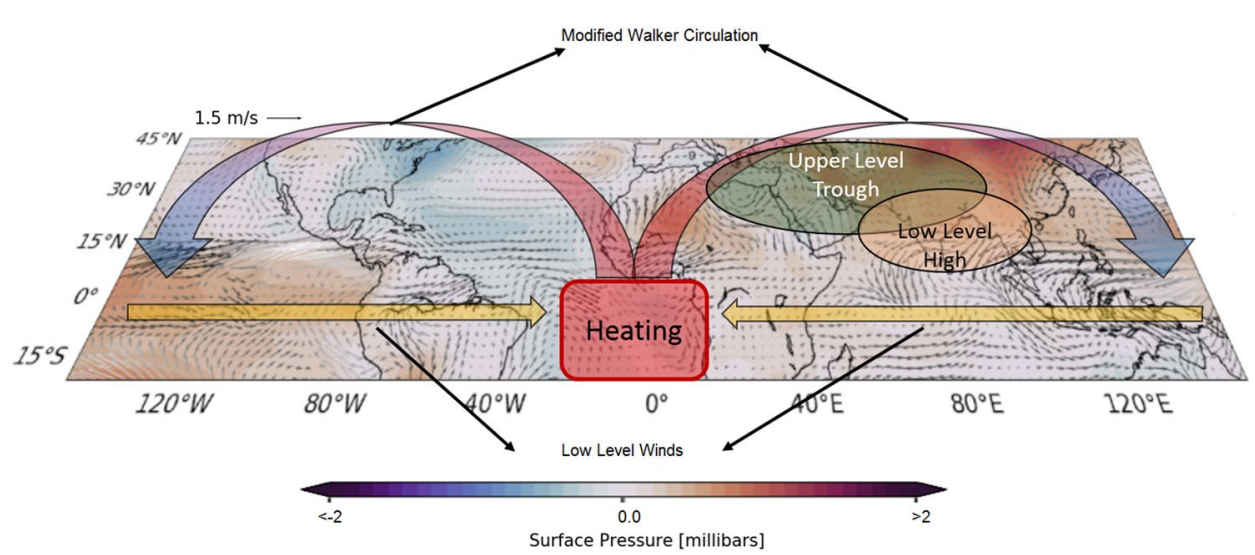


(a)

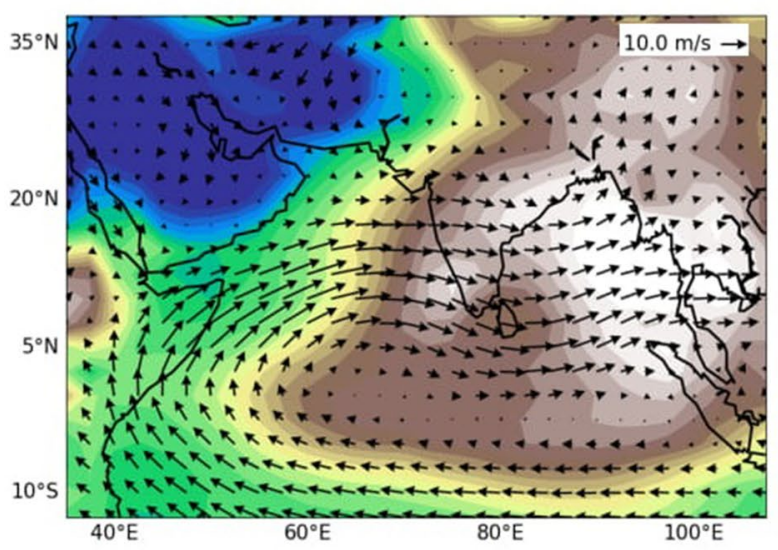

(b)

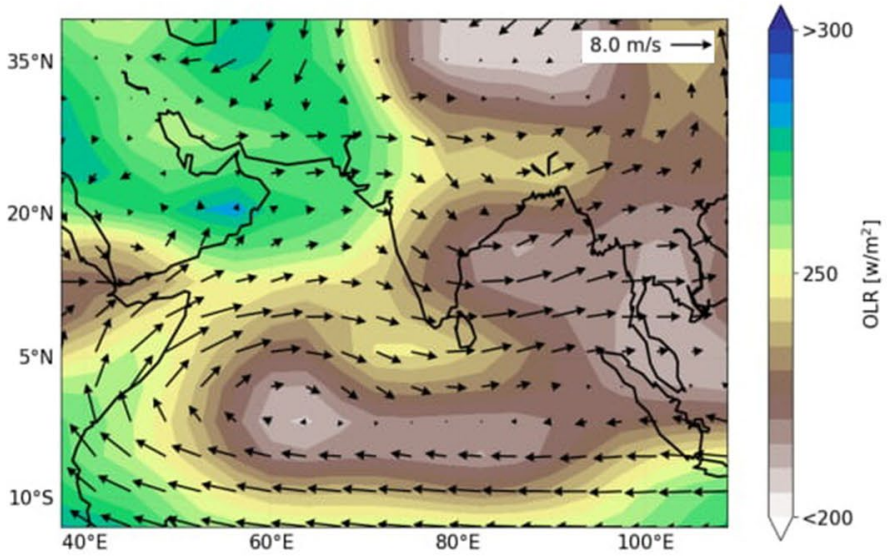

(c) Climatology of Indian rainfall from Jan to Dec

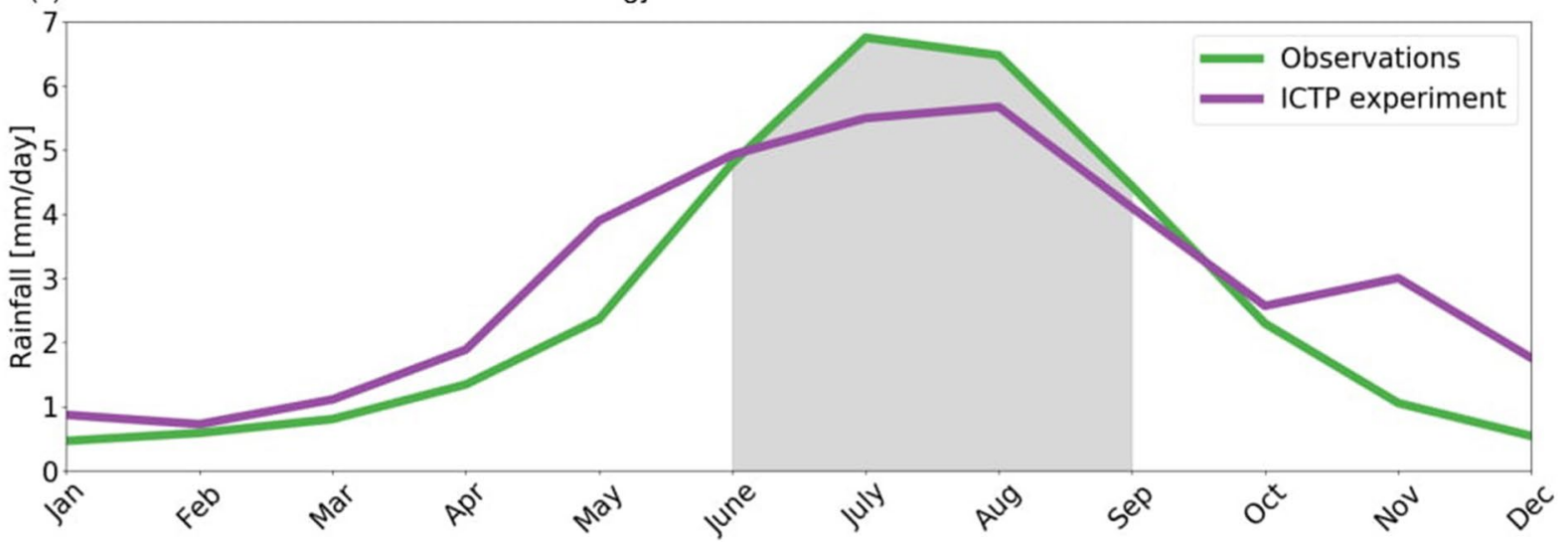

Fig. 4 ICTP AGCM model evaluation in representing the typical summer Indian summer monsoon features. a Depicts summer seasonal mean of winds at $850 \mathrm{hpa}$ and outgoing longwave radiation (OLR). b Same as a, but for ICTP AGCM. c Climatology of rain- fall over India [spatially averaged over $6.5^{\circ}-38.5^{\circ} \mathrm{N}, 66.5^{\circ}-100.5^{\circ} \mathrm{E}$ ] from both observations (green) and ICTP AGCM (pink). Grey shaded region represents the months (June-September) corresponding to summer monsoon season
With respect to ITCP AGCM perturbation study, we conduct two sets of experiments by superimposing positive (Fig. 5a) and negative anomaly (Fig. 5b) of SST to the seasonal climatology for JJAS months in the south Atlantic region. The positive SASST forcing resulted in a decrease in vertical wind shear over AS (Fig. 5c) due to anomalous easterlies (westerlies) at 850 (200) hpa; and this bears a strong agreement with the observations (Fig. 2). The negative SASST forcing, on the other hand, responded opposite to that of positive SASST forcing (Fig. 5d). Thus, these results further confirm the effect of SASST in changing the characteristics of lower (upper) level winds, further leading to changes in vertical wind shear. Analysing the premonsoon cyclones over AS, Zhang and Villarini (2019) found a significant positive correlation with the warming of the south Atlantic Ocean and the frequency of cyclones. Similar to our study, they also identified a reduced vertical wind shear to the warming of SASST. Considering this, and also from previous studies (Evan et al. 2011; Rajeevan et al. 2013), which reported a favourable condition of reduced vertical shear to the formation of cyclone genesis, we further perform the analysis pertaining to the frequencies of monsoon (JJAS) cyclones over AS during SASST phases. Figure $6 \mathrm{a}$ shows the total number of AS cyclones for the period 1979-2010. Many of these cyclones made a landfall over middle-east and Indian subcontinent regions. Additionally, we note that most of these cyclones were formed near the west coast of India. To underpin the role of SASST, we show AS cyclonic tracks during the positive (Fig. 6b) and negative phase (Fig. 6c). It is worth mentioning that frequencies were significantly higher during the positive phase than that of the negative phase of SASST. It should be noted that tropical cyclones over AS usually forms during pre- and post- summer monsoon seasons. This is due to the fact that during summer monsoon season, atmospheric monsoon circulation and associated 

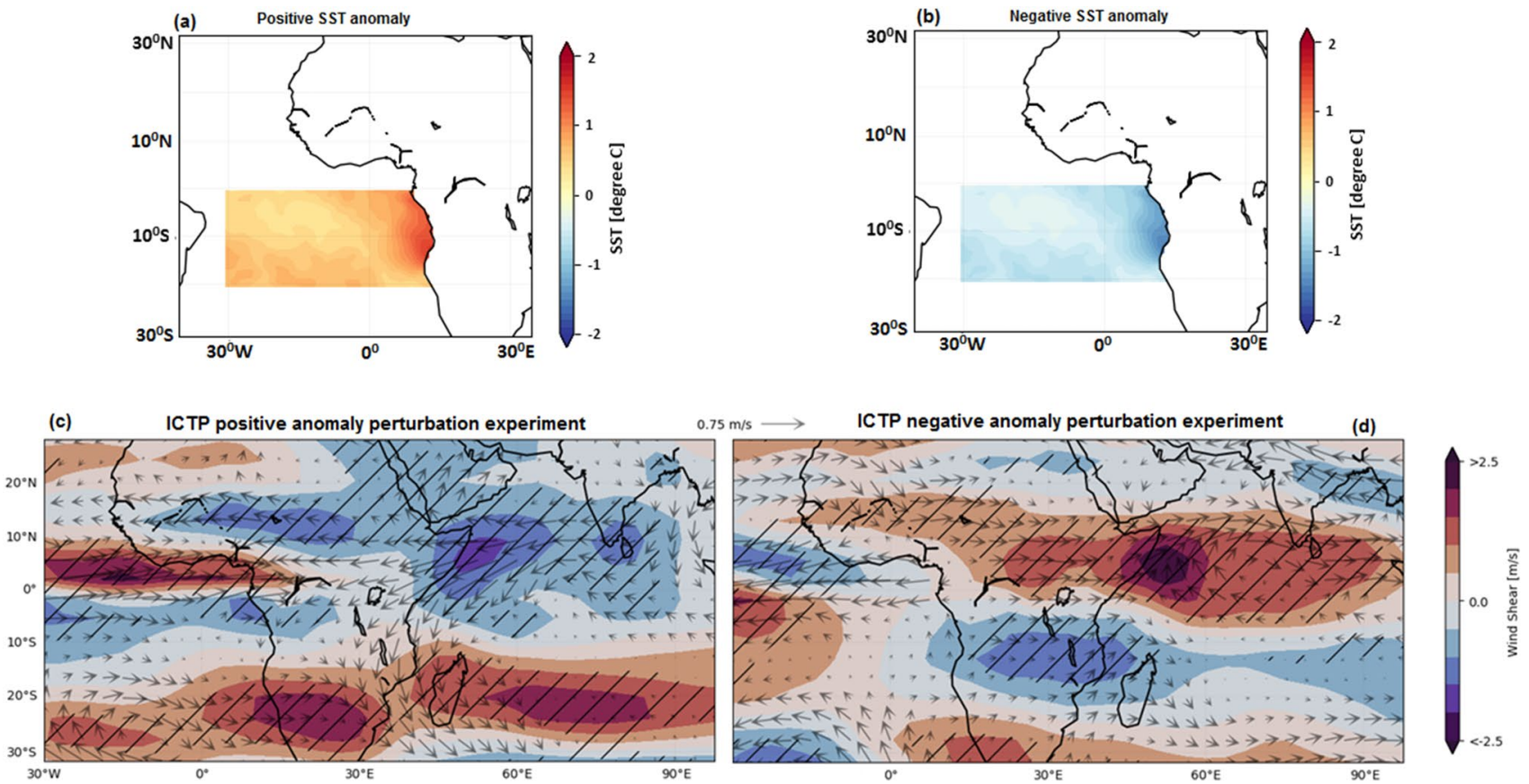

Fig. 5 SASST anomalies used in ICTP AGCM perturbation experiment for both positive (a) and negative (b) phase. Response of vertical wind shear and $850 \mathrm{hpa}$ wind to the perturbation experiment forced with positive (c) and negative SST anomalies (d). These

changes are estimated based on the seasonal climatology runs (CLIM). Hatching shows the regions where the differences in anomalies are different at $10 \%$ level
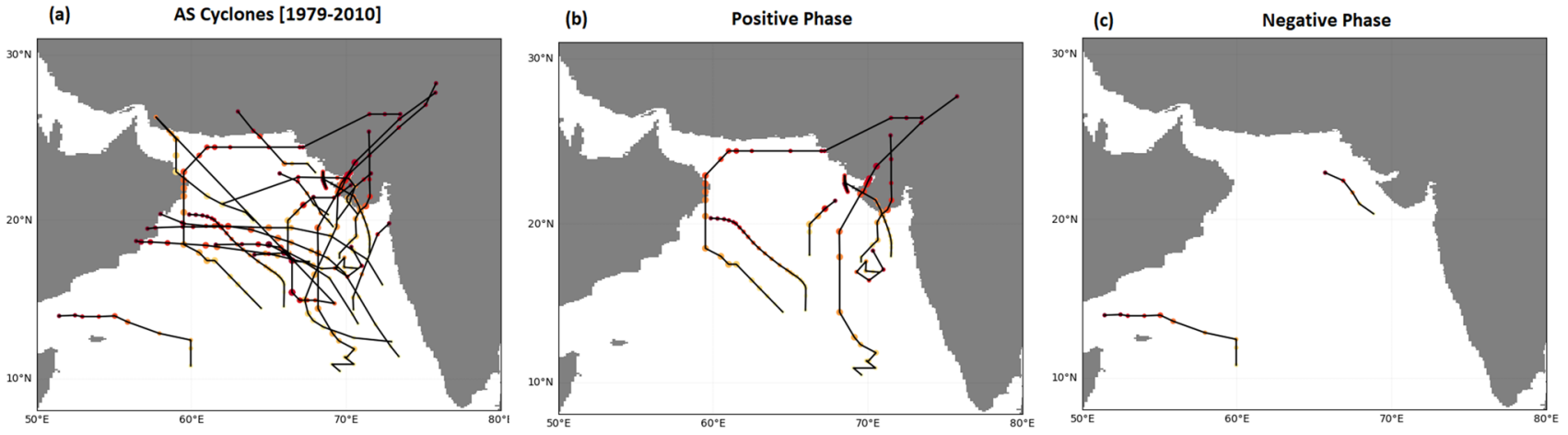

Depression

Fig. 6 a Total number of tropical cyclones $(\mathrm{N}=21)$ formed in the Arabian sea for the period of 1979-2010 during monsoon (JJAS) season, and with b positive $(\mathrm{N}=8)$ and $\mathbf{c}$ negative phase $(\mathrm{N}=2)$ of SASST. Change in color from yellow to red represent the increase in

strong vertical wind shear limits cyclone development and its intensification (Gray 1968; Evan and Camargo 2011; Evan et al. 2011). In our case, shown in Fig. 6, most of the pressure systems formed during the month of June (transition from pre-monsoon to monsoon season) and September (transition from monsoon to post- monsoon season) of the summer monsoon months. Having said that, the cyclonic storms which form during the month of June, does delay
Cyclonic Storm cyclone intensity (depression to sever cyclonic storm) during their lifespan. Average number of cyclones per positive phase event is statistically significant from that of negative phase

the monsoon onset and also impede the propagation of the monsoon within the subcontinent (Murakami et al. 2017). Thus, it's impact on the billion-strong population residing in India cannot be neglected. Our results based on both observations and climate model perturbation experiments perhaps provide a prominent evidence on the on the role of SASST in influencing the frequency of AS cyclones during JJAS season. 
The tropical cyclones (including AS region) and its fragments could be one of the significant drivers of precipitation extremes across different parts of the mid- and high- latitude regions. While, the contribution of cyclones to overall rainfall during JJAS is negligible (Khouakhi et al. 2017) in south Asia, its contribution towards extreme precipitation can hardly be overemphasized (Lau et al. 2008; Knight and Davis 2009; Prat and Nelson 2016). A recent study by Scoccimarro et al. (2020) identified the prominent role of tropical cyclones in significantly reducing the mean rainfall over tropical domain of Maritime Continent. They further add that this reduction in mean rainfall during active cyclones is due to net reduction in moisture transport to the Maritime Continent influenced by the cyclone-associated circulations.
On the Indian continent however, the moisture is primarily transported from the AS, which is approximately around $36 \%$ of the total moisture transported by the surrounding oceanic regions (Roxy et al. 2017). As we have already shown here that SASST increases the possibility of cyclones over AS, it is thus important to analyse the moisture transport conditions from the AS during the SASST phases.

Figure 7a shows JJAS climatology of moisture transport (in terms of IVT, based on Eq. 3) from 1951 to 2017. Majority of moisture is transported from the AS, western Indian Ocean and $\mathrm{BOB}$ - of which AS region appears to be the dominant one agreeing with Roxy et al. (2017) and Pathak et al. (2017). Along with increased IVT, we also notice a strengthening of westerlies at $850 \mathrm{hpa}$ which enables the

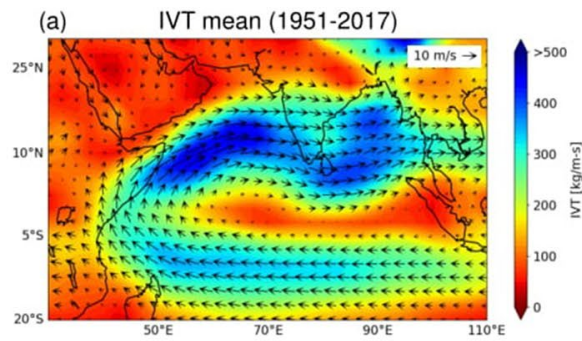

(b) Composite of IVT during (+) phase

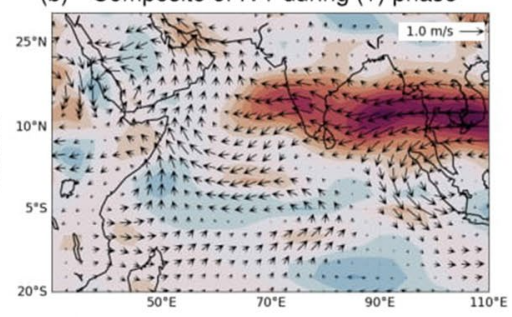

(c) Composite of IVT during (-) phase

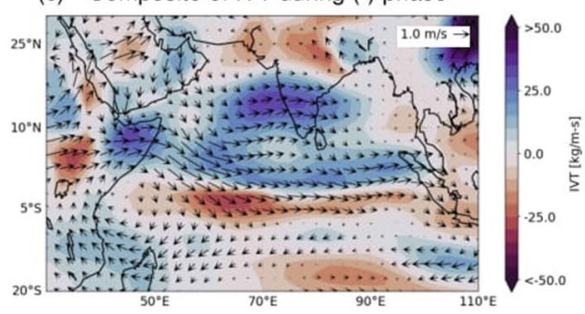

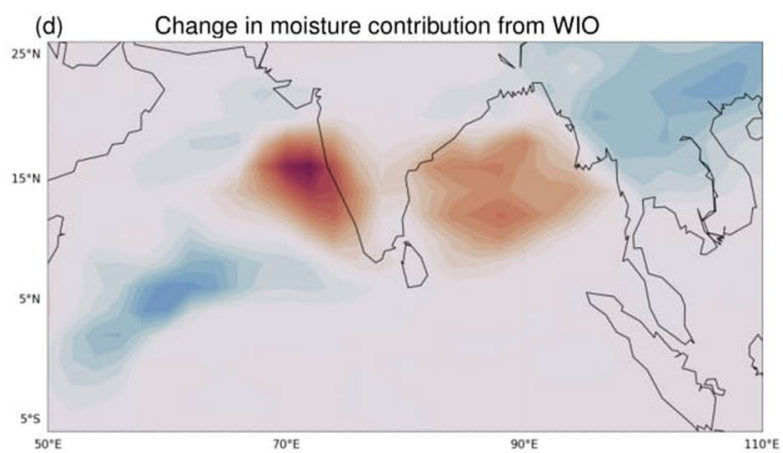
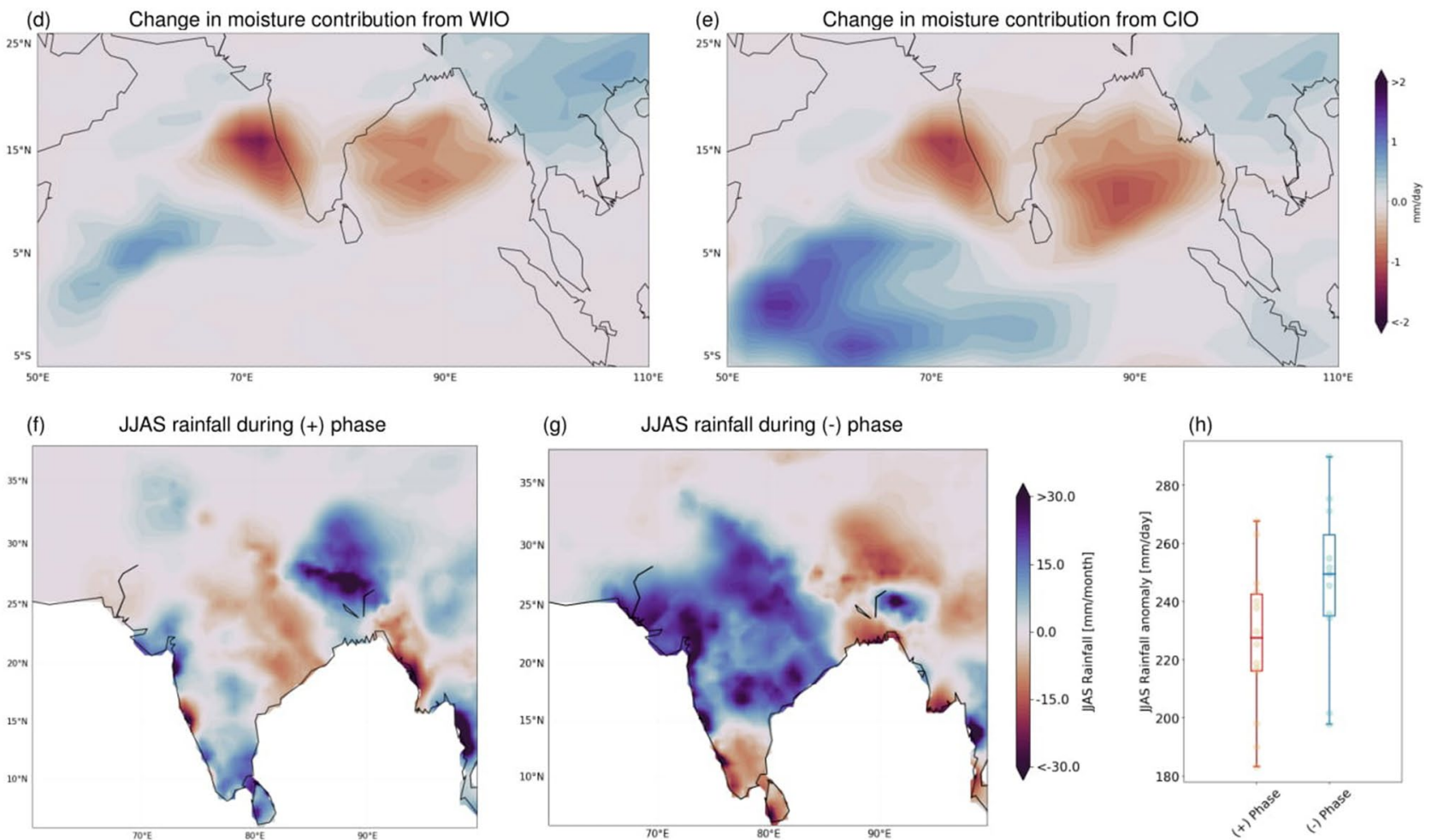

(g) JJAS rainfall during (-) phase
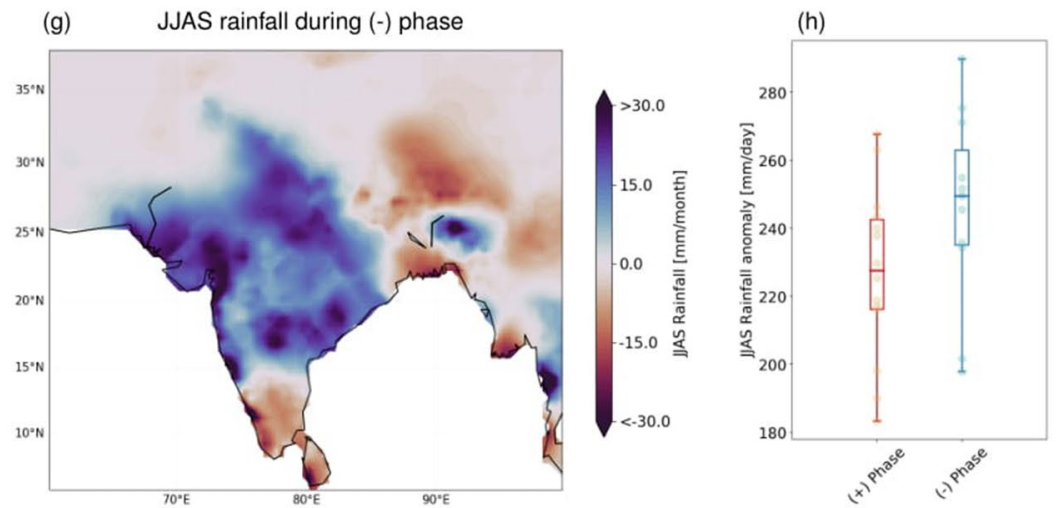

Fig. 7 Characteristics of moisture transport and JJAS rainfall during SASST phases. a Climatology of moisture transport in terms of IVT (shaded) and 850 hpa wind (vectors) during JJAS season from 1951 to 2018. b, c Are the anomalies of IVT and $850 \mathrm{hpa}$ wind during the positive and negative phase of SASST. The change in moisture contribution from WIO and CIO between positive and negative phase of
SASST are represented in $\mathbf{d}, \mathbf{e}$. $\mathbf{f}, \mathbf{g}$ are JJAS rainfall anomalies over south Asia for the positive and negative phases of SASST. The spatial mean comparison over the core monsoon zone $\left[18.5^{\circ} \mathrm{N}-25.5^{\circ} \mathrm{N}\right.$, $\left.74.5^{\circ} \mathrm{E}-84.5^{\circ} \mathrm{E}\right]$ for positive (red) and negative (blue) phase is provided in a boxplot (h) 
transport of moisture from source (AS) to sink (Indian continent). Further extension of analysis pertaining to the positive phase of SASST (Fig. 7b) depicts a weakening of lower wind westerlies together with declined eastward water flow into the Indian mainland. During the negative phase of SASST, prohibition of eastward water flow into the Indian mainland is nullified along with strengthening of westerlies at $850 \mathrm{hpa}$ (Fig. 7c). We further determine the moisture contributions from different Oceanic sources to the Indian mainland using a dynamic recycling model [refer Pathak et al. (2014) and Pathak et al. (2017) for more details]. Here, we consider two main oceanic sources viz., western Indian ocean (WIO, also encompasses AS) and central Indian Ocean (CIO), which are the important moisture sources for Indian subcontinent (Pathak et al. 2017), and also noticed in Fig. 7a. With the use of this model, we compare the difference in mean JJAS moisture contribution originated from the WIO (Fig. 7d) and the CIO (Fig. 7e) during negative phase and positive phase of SASST. A weakening of moisture transport from both of the sources (i.e. WIO and CIO) is observed during positive phase of SASST. The weakening of moisture contribution from WIO and CIO during positive phase is linked to weakening of vertical wind shear and hence weakening of monsoonal current. With the decline of moisture transport during the positive phase, the monsoon rainfall is seen to reduce (Fig. 7f) - the opposite can be noticed during the negative SASST phase (Fig. 7g). The spatially aggregated monsoon rainfall over the core monsoon zone is significantly lower during the positive phase compared to the negative phase of SASST (Fig. 7h). These analyses perhaps provide an evidence that SASST affects the monsoon rainfall over India along with modulating the genesis of cyclones over AS.

\subsection{Summary and conclusions}

Our study is an extension of previous studies (Pottapinjara et al. 2014, 2016; Sabeerali et al. 2019a), which discussed the relationship between Atlantic zonal mode/SASST and frequency of monsoon depression in $\mathrm{BoB}$ and its consequences in reducing the strength of the monsoon. Nonetheless, these studies overlooked the influence of SASST over AS basin, whose moisture contribution to the Indian mainland during summer monsoon season is relatively more than the BoB (Roxy et al. 2017). Furthermore, Pathak et al. (2017) showed that contribution of the WIO (which includes the AS) to Indian land mass during initial phase of monsoon is much larger (35-40\%) than the moisture contribution from the BoB. This perhaps indicates that understanding the dynamics of Arabian Sea is more important, which were lacking in the literature. Based on the analysis presented in this study, we underpin the significant role played by SASST on the variability of Indian monsoon and on the frequencies of cyclone over AS; and its associated physical mechanisms. Reduced vertical wind shear due to warming of south Atlantic Ocean can be explained by a classical Matsuno-Gill response, which is consistent both with observations and climate model perturbation experiments. This reduced vertical wind shear aids in the development of cyclone genesis over AS and also prohibits the transport of moisture to the Indian mainland, eventually causing weakening of monsoon circulation-leading to dry condition over India. Our analysis provides sufficient evidence to use the SST anomalies in the south Atlantic Ocean as a potential predictor for both AS cyclones and Indian monsoon strength at seasonal time scales, which is misrepresented by most forecast models (Sabeerali et al. 2019b).

SST over Atlantic Ocean has significantly warmed during recent past (Saunders and Lea 2008). Given a significant role of SASST on AS cyclones and JJAS Indian rainfall, we went one step further and examined the relative role played by the human-induced climate change in driving the increasing trend of SST - with the use of state-of-the-art climate model simulation from CMIP5 (details provided in Table 1). Figure 8a shows the similarity between Hist and HistGhG experiments, especially during the late 20th century-the period during which the effect of anthropogenic warming was apparent (Diffenbaugh et al. 2015). Moreover, decadal variability of Hist simulations are consistent with observed SASST patterns, specifically during post 1960s (inset of Fig. 8a). Further, we perform relative importance analysis [detailed in Johnson and LeBreton (2004), Grömping (2007) and Vittal et al. (2020c)] to quantify the contribution of HistGHG towards changes in SASST. We notice a significant contribution from HistGHG towards demonstrating the observed SST pattern compared to the HistNAT during post 1960 (Fig. 8b). If the GhG emission is not controlled with proper mitigation measures, SASST will increase strongly towards the end of the 21th century as shown by RCP 8.5 and 4.5 scenarios (Fig. 8a).

As the warming of the Atlantic Ocean due to increased GhG emission is apparent (Xie et al. 2010), more frequent cyclones in AS and weakening of monsoon over India can be expected in near future. One way to tackle this issue is by adhering to recent Paris Agreement, which urges all nations to restrict emission such that the warming level does not exceed $2{ }^{\circ} \mathrm{C}$ compared to pre-industrial levels and to pursue the limit of $1.5^{\circ} \mathrm{C}$ (Vicedo-cabrera et al. 2018). Studies reported a wide range of benefits, such as reduced tropical cyclones (Wen et al. 2019) to increase in mean precipitation over India (Maharana et al. 2020), if the warming limit is set to $1.5^{\circ} \mathrm{C}$ based on the Paris agreement.

Acknowledgements We thank Dr. Fred Kucharski for providing access to the ICTP AGCM model. Authors also acknowledges the efforts of 

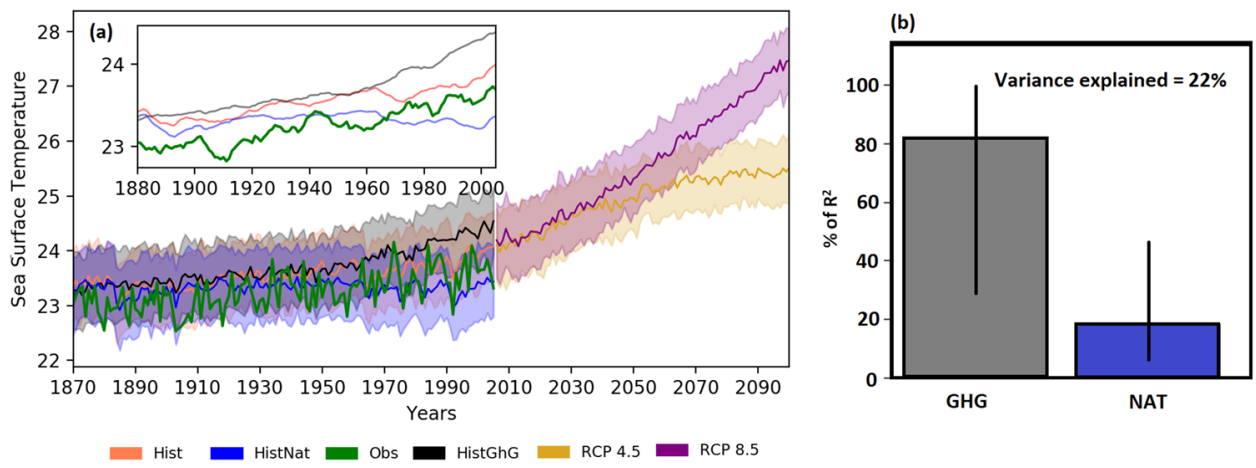

Fig. 8 a Yearly variation of SASST during JJAS season based on observational data-set and the ensemble $(\mathrm{N}=10)$ of climate model simulations from CMIP5 under different experimental scenarios: natural only historical (HistNat), green-house emission-only (HistGhG), all-forcings historical (Hist), and two future RCPs (4.5, and 8.5). Thick solid lines show the multimodel means, and filled areas

different organizations for making the data available, which includes CMIP5 data from the World Climate Research Programme's Working Group on Coupled Modelling; CRU, HadISST and NCEP reanalysis database. Tropical cyclone track data for the Arabian Sea in the form of eAtlas from India Meteorological Department. The cyclone e-Atlas is produced by India Metorological Department, Cyclone Warning Research Centre (CWRC) and Regional Meteorological Centre (RMC), Chennai. VH acknowledges Dr. Wei Zhang, Univeristy of Iowa, for his contribution in knowledge sharing. Many useful discussions with him helped $\mathrm{VH}$ to generate and address the research problem which is presented in this article. VH also acknowledges Prof. Mat Collins, University of Exeter, for his helpful suggestions and comments. Data analysis was conducted at the High-Performance Computing (HPC) Cluster EVE, a joint effort of both the Helmholtz Centre for Environmental Research-UFZ and the German Centre for Integrative Biodiversity Research (iDiv) Halle-Jena-Leipzig. Finally, we would like to thank two anonymous reviewers and the Editor for their constructive comments, which improved the quality of the manuscript.

Funding Open Access funding enabled and organized by Projekt DEAL.

Open Access This article is licensed under a Creative Commons Attribution 4.0 International License, which permits use, sharing, adaptation, distribution and reproduction in any medium or format, as long as you give appropriate credit to the original author(s) and the source, provide a link to the Creative Commons licence, and indicate if changes were made. The images or other third party material in this article are included in the article's Creative Commons licence, unless indicated otherwise in a credit line to the material. If material is not included in the article's Creative Commons licence and your intended use is not permitted by statutory regulation or exceeds the permitted use, you will need to obtain permission directly from the copyright holder. To view a copy of this licence, visit http://creativecommons.org/licenses/by/4.0/.

\section{References}

Barimalala R, Bracco A, Kucharski F (2012) The representation of the South Tropical Atlantic teleconnection to the Indian Ocean in the AR4 coupled models. Clim Dyn 38(5-6):1147-1166 represent $95 \%$ confidence intervals based on the sampling distribution of mean. The inset plot in a represents variations of SASST, but with 10-year moving average. Relative importance analysis of HistGhG and HistNaT simulations on observed SASST for post-1960 (b). The bar plot shows the contribution of each simulations, whereas error bar represents the bootstrapped $95 \%$ confidence for 1000 re-samples

Bollasina MA, Ming Y, Ramaswamy V (2011) Anthropogenic aerosols and the weakening of the South Asian summer monsoon. Science 334(6055):502-505

Burls NJ, Reason CC, Penven P, Philander SG (2012) Energetics of the tropical Atlantic zonal mode. J Clim 25(21):7442-7466

Chen TC (2003) Maintenance of summer monsoon circulations: a planetary-scale perspective. J Clim 16(12):2022-2037

Diffenbaugh NS, Swain DL, Touma D (2015) Anthropogenic warming has increased drought risk in California. Proc Natl Acad Sci 112(13):3931-3936

Evan AT, Camargo SJ (2011) A climatology of Arabian Sea cyclonic storms. J Clim 24(1):140-158

Evan AT, Kossin JP, Ramanathan V (2011) Arabian Sea tropical cyclones intensified by emissions of black carbon and other aerosols. Nature 479(7371):94-97

Feudale L, Kucharski F (2013) A common mode of variability of African and Indian monsoon rainfall at decadal timescale. Clim Dyn 41(2):243-254

Gill AE (1980) Some simple solutions for heat-induced tropical circulation. Q J R Meteorol Soc 106(449):447-462

Gray WM (1968) Global view of the origin of tropical disturbances and storms. Mon Weather Rev 96(10):669-700

Grömping U (2007) Estimators of relative importance in linear regression based on variance decomposition. Am Stat 61(2):139-147

Johnson JW, LeBreton JM (2004) History and use of relative importance indices in organizational research. Org Res Methods 7(3):238-257

Ju J, Slingo J (1995) The Asian summer monsoon and ENSO. Q J R Meteorol Soc 121(525):1133-1168

Kalnay E, Kanamitsu M, Kistler R, Collins W, Deaven D, Gandin L, Iredell M, Saha S, White G, Woollen J, Zhu Y (1996) The NCEP/NCAR 40-year reanalysis project. Bull Am Meteorol Soc 77(3):437-472

Khouakhi A, Villarini G, Vecchi GA (2017) Contribution of tropical cyclones to rainfall at the global scale. J Clim 30(1):359-372

Kitoh A, Endo H, Krishna Kumar K, Cavalcanti IF, Goswami P, Zhou $\mathrm{T}$ (2013) Monsoons in a changing world: a regional perspective in a global context. J Geophys Res Atmos 118(8):3053-3065

Knight DB, Davis RE (2009) Contribution of tropical cyclones to extreme rainfall events in the southeastern United States. J Geophys Res Atmos 114:D23102. https://doi.org/10.1029/2009J D012511 
Kucharski F, Bracco A, Yoo JH, Molteni F (2007) Low-frequency variability of the Indian monsoon-ENSO relationship and the tropical Atlantic: the "weakening" of the 1980s and 1990s. J Clim 20(16):4255-4266

Kucharski F, Bracco A, Yoo JH, Molteni F (2008) Atlantic forced component of the Indian monsoon interannual variability. Geophys Res Lett 35:L04706. https://doi.org/10.1029/2007GL0330 37

Kucharski F, Bracco A, Yoo JH, Tompkins AM, Feudale L, Ruti P, Dell'Aquila A (2009) A Gill-Matsuno-type mechanism explains the tropical Atlantic influence on African and Indian monsoon rainfall. Q J R Meteorol Soc 135(640):569-579

Kucharski F, Bracco A, Barimalala R, Yoo JH (2011) Contribution of the east-west thermal heating contrast to the South Asian Monsoon and consequences for its variability. Clim Dyn 37(3-4):721-735

Kucharski F, Molteni F, King MP, Farneti R, Kang IS, Feudale L (2013) On the need of intermediate complexity general circulation models: a "SPEEDY" example. Bull Am Meteorol Soc 94(1):25-30

Lau KM, Zhou YP, Wu HAT (2008) Have tropical cyclones been feeding more extreme rainfall? J Geophys Res Atmos 113:D23113. https://doi.org/10.1029/2008JD009963

Lavers DA, Villarini G, Allan RP, Wood EF, Wade AJ (2012) The detection of atmospheric rivers in atmospheric reanalyses and their links to British winter floods and the large-scale climatic circulation. J Geophys Res Atmos 117:D20106. https://doi. org/10.1029/2012JD018027

Lavers DA, Ralph FM, Waliser DE, Gershunov A, Dettinger MD (2015) Climate change intensification of horizontal water vapor transport in CMIP5. Geophys Res Lett 42(13):5617-5625

Levine RC, Turner AG (2012) Dependence of Indian monsoon rainfall on moisture fluxes across the Arabian Sea and the impact of coupled model sea surface temperature biases. Clim Dyn 38(11-12):2167-2190

Lübbecke JF, Böning CW, Keenlyside NS, Xie SP (2010) On the connection between Benguela and equatorial Atlantic Niños and the role of the South Atlantic Anticyclone. J Geophys Res Oceans 115:C09015. https://doi.org/10.1029/2009JC005964

Lübbecke JF, Rodríguez-Fonseca B, Richter I, Martín-Rey M, Losada T, Polo I, Keenlyside NS (2018) Equatorial Atlantic variability-modes, mechanisms, and global teleconnections. WIREs Clim Change 9(4):e527. https://doi.org/10.1002/wcc.527

Maharana P, Dimri AP, Choudhary A (2020) Future changes in Indian summer monsoon characteristics under 1.5 and $2^{\circ} \mathrm{C}$ specific warming levels. Clim Dyn 54(12):507-523

Martinez JA, Dominguez F (2014) Sources of atmospheric moisture for the La Plata River basin. Clim Dyn 27(17):6737-6753

Mitchell TD, Jones PD (2005) An improved method of constructing a database of monthly climate observations and associated highresolution grids. Int J Climatol 25(6):693-712

Molteni F (2003) Atmospheric simulations using a GCM with simplified physical parametrizations. I: Model climatology and variability in multi-decadal experiments. Clim Dyn 20(2-3):175-191

Mooley DA (1973) Some aspects of Indian monsoon depression and associated rainfall. Mon Weather Rev 101:271-280

Murakami H, Vecchi GA, Underwood S (2017) Increasing frequency of extremely severe cyclonic storms over the Arabian Sea. Nat Clim Chang 7(12):885-889

Pathak A, Ghosh S, Kumar P (2014) Precipitation recycling in the Indian subcontinent during summer monsoon. J Hydrometeorol 15(5):2050-2066

Pathak A, Ghosh S, Kumar P, Murtugudde R (2017) Role of oceanic and terrestrial atmospheric moisture sources in intraseasonal variability of Indian summer monsoon rainfall. Sci Rep 7:12729. https://doi.org/10.1038/s41598-017-13115-7
Paul S, Ghosh S, Oglesby R, Pathak A, Chandrasekharan A, Ramsankaran RA (2016) Weakening of Indian summer monsoon rainfall due to changes in land use land cover. Sci Rep 6:32177. https://doi.org/10.1038/srep32177

Pottapinjara V, Girishkumar MS, Ravichandran M, Murtugudde $R$ (2014) Influence of the Atlantic zonal mode on monsoon depressions in the Bay of Bengal during boreal summer. J Geophys Res Atmos 119(11):6456-6469

Pottapinjara V, Girishkumar MS, Sivareddy S, Ravichandran M, Murtugudde R (2016) Relation between the upper ocean heat content in the equatorial Atlantic during boreal spring and the Indian monsoon rainfall during June-September. Int J Climatol 36(6):2469-2480

Prat OP, Nelson BR (2016) On the link between tropical cyclones and daily rainfall extremes derived from global satellite observations. J Clim 29(17):6127-6135

Rajeevan M, Srinivasan J, Niranjan Kumar K, Gnanaseelan C, Ali MM (2013) On the epochal variation of intensity of tropical cyclones in the Arabian Sea. Atmos Sci Lett 14(4):249-255

Rayner NA, Parker DE, Horton EB, Folland CK, Alexander LV, Rowell DP, Kent EC, Kaplan A (2014) Global analyses of sea surface temperature, sea ice, and night marine air temperature since the late nineteenth century. J Geophys Res Atmos 108:4407. https:// doi.org/10.1029/2002JD002670

Roxy MK, Ritika K, Terray P, Murtugudde R, Ashok K, Goswami BN (2015) Drying of Indian subcontinent by rapid Indian Ocean warming and a weakening land-sea thermal gradient. Nat Commun 6:7423. https://doi.org/10.1038/ncomms8423

Roxy MK, Ghosh S, Pathak A, Athulya R, Mujumdar M, Murtugudde R, Terray P, Rajeevan M (2017) A threefold rise in widespread extreme rain events over central India. Nat Commun 8:708. https ://doi.org/10.1038/s41467-017-00744-9

Roy I, Tedeschi RG, Collins M (2019) ENSO teleconnections to the Indian summer monsoon under changing climate. Int J Climatol 39(6):3031-3042

Sabeerali CT, Ajayamohan RS, Bangalath HK, Chen N (2019a) Atlantic zonal mode: an emerging source of Indian summer monsoon variability in a warming world. Geophys Res Lett 46(8):4460-4467

Sabeerali CT, Ajayamohan RS, Rao SA (2019b) Loss of predictive skill of indian summer monsoon rainfall in NCEP CFSv2 due to misrepresentation of Atlantic zonal mode. Clim Dyn 52(7-8):4599-4619

Saunders MA, Lea AS (2008) Large contribution of sea surface warming to recent increase in Atlantic hurricane activity. Nature 451(7178):557-560

Scoccimarro E, Gualdi S, Bellucci A, Peano D, Cherchi A, Vecchi GA, Navarra A (2020) The typhoon-induced drying of the Maritime Continent. Proc Natl Acad Sci 117(8):3983-3988

Sharma T, Vittal H, Karmakar S, Ghosh S (2020) Increasing agricultural risk to hydro-climatic extremes in India. Environ Res Lett 15(3):034010. https://doi.org/10.1088/1748-9326/ab63e1

Shashikanth K, Ghosh S, Vittal H, Karmakar S (2018) Future projections of Indian summer monsoon rainfall extremes over India with statistical downscaling and its consistency with observed characteristics. Clim Dyn 51(1-2):1-15

Taylor KE, Stouffer RJ, Meehl GA (2012) An overview of CMIP5 and the experiment design. Bull Am Meteorol Soc 93(4):485-498

Vecchi GA, Soden BJ, Wittenberg AT, Held IM, Leetmaa A, Harrison MJ (2006) Weakening of tropical Pacific atmospheric circulation due to anthropogenic forcing. Nature 441(7089):73-76

Vicedo-Cabrera AM, Guo Y, Sera F, Huber V, Schleussner CF, Mitchell D, Tong S, Coelho MD, Saldiva PH, Lavigne E, Correa PM (2018) Temperature-related mortality impacts under and beyond Paris Agreement climate change scenarios. Clim Change 150(3-4):391-402 
Vishnu S, Francis PA, Shenoi SS, Ramakrishna SS (2016) On the decreasing trend of the number of monsoon depressions in the Bay of Bengal. Environ Res Lett 11(1):014011. https://doi. org/10.1088/1748-9326/11/1/014011

Vittal H, Karmakar S, Ghosh S, Murtugudde R (2020a) A comprehensive India-wide social vulnerability analysis: highlighting its influence on hydro-climatic risk. Environ Res Lett 15(1):014005. https://doi.org/10.1088/1748-9326/ab6499

Vittal H, Villarini G, Zhang W (2020b) Early prediction of the Indian summer monsoon rainfall by the Atlantic Meridional Mode. Clim Dyn 54(3-4):2337-2346

Vittal H, Villarini G, Zhang W (2020c) On the role of the atlantic ocean in exacerbating indian heat waves. Clim Dyn 54(3):1887-1896

Wang B, Xu S, Wu L (2012) Intensified Arabian Sea tropical storms. Nature 489(7416):E1-E2. https://doi.org/10.1038/nature11470

Wen S, Wang Y, Su B, Gao C, Chen X, Jiang T, Tao H, Fischer T, Wang G, Zhai J (2019) Estimation of economic losses from tropical cyclones in China at $1.5^{\circ} \mathrm{C}$ and $2.0^{\circ} \mathrm{C}$ warming using the regional climate model COSMO-CLM. Int J Climatol 39(2):724-737

Xie SP, Deser C, Vecchi GA, Ma J, Teng H, Wittenberg AT (2010) Global warming pattern formation: sea surface temperature and rainfall. J Clim 23(4):966-986

Yadav RK, Srinivas G, Chowdary JS (2018) Atlantic Niño modulation of the Indian summer monsoon through Asian jet. NPJ Clim Atmos Sci 1(1):23. https://doi.org/10.1038/s41612-018-0029-5

Zhang W, Villarini G (2019) On the role of the Atlantic Ocean in forcing tropic cyclones in the Arabian Sea. Atmos Res 220:120-124

Publisher's Note Springer Nature remains neutral with regard to jurisdictional claims in published maps and institutional affiliations. 